\title{
Surgical teaching does not increase the risk of intraoperative adverse events
}

\author{
Basile Pache $^{1}$ (D) $\cdot$ Fabian Grass $^{1} \cdot$ Nicolas Fournier $^{2} \cdot$ Martin Hübner $^{1} \cdot$ Nicolas Demartines $^{1} \cdot$ Dieter Hahnloser $^{1}$
}

Accepted: 10 August 2018 / Published online: 24 August 2018

(C) Springer-Verlag GmbH Germany, part of Springer Nature 2018

\begin{abstract}
Introduction Training and teaching are cornerstones in developing surgical skills. The present study aimed to compare intraoperative outcomes of colonic resections among fellows, consultants, and supervised trainees.

Methods Data of consecutive colonic resections including demographics, surgical details, and intraoperative outcomes were recorded in a prospectively maintained institutional database. All procedures were standardized and divided in three groups according to the main surgeons experience (fellow or consultant) and whether the procedure was taught. After weighting by inverse treatment probability, intraoperative adverse events including reactive conversion, blood loss, and operating time were compared between these three groups.

Results Six hundred sixty-four colectomies were analyzed between January 2014 and October 2017. Among them, 289 (43.5\%) were taught. After weighted propensity score analysis, there was no difference between the three groups (fellow taken as reference), for intraoperative adverse event rate (odd ratio (OR) consultant 1.448 (IQR 0.728-2.878), $p=0.282$; OR teaching 0.689 (IQR 0.295-1.609), $p=0.381$ ), operating time (beta coefficient $0.76(-21.91-23.42), p=0.947$; beta coefficient -10.79 $(-28.34-6.75), p=0.919)$, conversion rates (OR $0.748(0.329-1.515), p=0.412$; OR $1.025(0.537-1.954), p=0.940)$, preemptive conversion (OR $1.994(0.198-20.032), p=0.552$; OR $0.659(0.145-2.991), p=0.583)$, intraoperative blood loss (beta coefficient $21.19(-25.87-68.25), p=0.368$; beta coefficient $-12.34(-56.13-31.44), p=0.573)$, intraoperative transfusion (OR $1.962(0.813-4.735), p=0.127$; OR $0.670(0.260-1.727), p=0.397)$, and rates of unusual bleeding (OR $1.273(0.698-$ $2.321), p=0.422$; OR $0.572(0.290-1.126), p=0.099)$. Time to preemptive conversion was shorter when procedures were performed by consultants (beta coefficient $-25.51(-47.71$ to -3.31$), p=0.025)$, while no difference was found for the teaching group (beta coefficient $4.48(-30.95-40.62), p=0.788)$.

Conclusion Within a standardized teaching environment, colonic resections were safely performed regardless of the surgical setting in the present cohort. Teaching does not increase intraoperative adverse events.
\end{abstract}

Keywords Teaching $\cdot$ Surgery $\cdot$ Outcomes $\cdot$ Complications $\cdot$ Adverse event

\section{Introduction}

Basile Pache and Fabian Grass contributed equally to this work.

Basile Pache and Fabian Grass shared first authorship.

Electronic supplementary material The online version of this article (https://doi.org/10.1007/s00384-018-3143-2) contains supplementary material, which is available to authorized users.

Nicolas Demartines

demartines@chuv.ch

1 Department of Visceral Surgery, Lausanne University Hospital CHUV, Rue du Bugnon 46, CH - 1011 Lausanne, Switzerland

2 Institute for Social and Preventive Medicine (IUMSP), Lausanne University Hospital CHUV, Lausanne, Switzerland
Teaching is a cornerstone in developing surgical skills. The traditional adage: "see one, do one, teach one" raised questions about patients' safety and was therefore studied regarding postoperative complications [1]. Interestingly, experience of the surgeon was associated with postoperative surgical but not with intraoperative complications [2]. Further, it was demonstrated that postoperative surgical complications were rather the result of non-technical factors [3]. A structured and standardized teaching environment with step-by-step definition of surgical procedure allowing trainees to constantly achieve surgical milestones has been repeatedly associated with non-adverse postoperative outcomes [4-6]. However, less is known about the influence of teaching on intraoperative 
adverse events that are directly related to technical skills and surgical experience.

The aim of the present study was therefore to analyze the impact of teaching on intraoperative outcomes.

\section{Methods}

\section{Patients and procedures}

All consecutive patients undergoing colonic resections between January 2014 and October 2017 at the tertiary academic center of Lausanne University Hospital (CHUV) were included. Surgeries were grouped as open and laparoscopic colectomies (right-sided including transverse colectomies, left-sided and total) and Hartmann reversals in an elective or emergency setting.

This study was approved by the Institutional Review Board (Commission cantonale d'éthique de la recherche sur l'être humain CER-VD, \# 2017-01971). The study was conducted according to the STROBE criteria and registered under www. researchregistry.com (UIN research registry \# 38444).
Demographic and surgical characteristics were prospectively assessed by the main operating surgeon in an a priori designed dedicated database; accuracy of data entry was cross-checked monthly by the consultant surgeons (DH and $\mathrm{MH})$. These items are displayed in Tables 1 and 2, respectively. Indications for surgery (diagnosis) were either diverticulitis, colon cancer, or inflammatory bowel disease (IBD). The group "colectomies within other procedure" contains colectomies which were performed as additional secondary procedure within surgeries for other primary indications or pathologies (mainly major debulking surgeries (i.e., for peritoneal metastasis or sarcoma), or benign indications (i.e., endometriosis, polyps)). Remaining procedures which could not be assigned to either diagnosis were denominated "other indications." Excluded were rectum procedures, total proctocolectomies and ileo-anal pouch, and stoma procedures (i.e., loop ileostomy closures as main operation). Immunosuppression was defined as ongoing immunosuppressive treatment (i.e., steroids) by the time of surgery. Emergency procedures were procedures performed during non-planned admission. Wound contamination class was assessed by the main surgeon based on four categories (I-

Table 1 Baseline characteristics

\begin{tabular}{|c|c|c|c|c|}
\hline Number of patients (\%) & $\begin{array}{l}\text { Fellow } \\
190(28.6)\end{array}$ & $\begin{array}{l}\text { Consultant } \\
185(27.9)\end{array}$ & $\begin{array}{l}\text { Teaching } \\
289(43.5)\end{array}$ & $p$-value \\
\hline \multicolumn{5}{|l|}{ Gender } \\
\hline Female $(\%)$ & $82(43.2)$ & $90(48.7)$ & $125(43.3)$ & \\
\hline Male $(\%)$ & $108(56.8)$ & $95(51.3)$ & $164(56.8)$ & 0.451 \\
\hline Age (yrs)(median) & 70 (IQR 58-79) & 66 (IQR 51-74) & 69 (IQR 56-78) & 0.005 \\
\hline \multicolumn{5}{|l|}{ Age category } \\
\hline 70 or younger & $96(50.5)$ & $118(63.8)$ & $157(54.3)$ & \\
\hline Older than 70 & $94(49.5)$ & $67(36.2)$ & $132(45.7)$ & 0.028 \\
\hline BMI $\left[\mathrm{kg} / \mathrm{m}^{\wedge} 2\right]$ (median) & 26 (IQR 22-31) & 25 (IQR 21-29) & 25 (IQR 22-28) & 0.291 \\
\hline BMI lower than $18.5(\%)$ & $12(8.5)$ & $9(6.2)$ & $20(8.1)$ & 0.715 \\
\hline BMI greater than $25(\%)$ & $79(56.0)$ & $72(49.3)$ & $132(53.4)$ & 0.513 \\
\hline \multicolumn{5}{|l|}{ ASA category } \\
\hline $1-2(\%)$ & $64(39.3)$ & $111(70.3)$ & $141(52.2)$ & \\
\hline $3-5(\%)$ & $99(60.7)$ & $47(29.7)$ & $129(47.8)$ & $<0.001$ \\
\hline \multicolumn{5}{|l|}{ Diagnosis } \\
\hline Colon cancer $(\%)$ & $53(28.2)$ & $63(34.4)$ & $133(46.5)$ & \\
\hline Crohn's disease (\%) & $4(2.1)$ & $11(6.0)$ & $24(8.4)$ & \\
\hline Diverticulitis (\%) & $98(52.1)$ & $42(23.0)$ & $89(31.1)$ & \\
\hline Other $(\%)$ & $15(8.0)$ & $16(8.7)$ & $20(7.0)$ & \\
\hline Colectomy within other procedure (\%) & $18(9.6)$ & $51(27.9)$ & $20(7.0)$ & $<0.001$ \\
\hline Charlson $>3(\%)$ & $51(26.8)$ & $25(13.5)$ & $55(19)$ & 0.005 \\
\hline Malignancy & $58(34.5)$ & $71(47.3)$ & $139(51.3)$ & 0.002 \\
\hline Immunosuppression & $20(10.5)$ & $16(8.7)$ & $43(14.9)$ & 0.098 \\
\hline Previous surgeries & $93(49.2)$ & $108(59.0)$ & $164(56.8)$ & 0.129 \\
\hline
\end{tabular}

BMI - Body Mass Index, ASA - American Society of Anaesthesiologists, Charlson - Charlson comorbidity score. Significant values are indicated in bold characters 
Table 2 Surgical details

\begin{tabular}{lllll}
\hline & $\begin{array}{l}\text { Fellow } \\
\text { Number of patients (\%) }\end{array}$ & $\begin{array}{l}\text { Consultant } \\
185(27.9)\end{array}$ & $\begin{array}{l}\text { Teaching } \\
289(43.5)\end{array}$ & $\begin{array}{l}p \text { - } \\
\text { value }\end{array}$ \\
\hline $\begin{array}{l}\text { Procedure } \\
\text { Left }\end{array}$ & $75(39.7)$ & $74(40.0)$ & $139(48.1)$ & \\
$\quad$ Right & $78(41.3)$ & $73(39.5)$ & $104(36.0)$ & \\
$\quad$ Total & $11(5.8)$ & $4(2.2)$ & $9(3.1)$ & $18(6.2)$ \\
$\quad 16(8.5)$ & $12(6.5)$ & $19(6.6)$ & 0.057 \\
$\quad$ Hartmann reversal & $9(8.5)$ & $22(11.9)$ & $77(27.1)$ & $<\mathbf{0 . 0 0 1}$ \\
$\quad$ Ether & $109(57.7)$ & $40(22.4)$ & & \\
Wound Contamination class & $135(71.1)$ & $150(81.1)$ & $251(87.2)$ & \\
$\quad \begin{array}{l}\text { 2 or less } \\
\quad \text { or more }\end{array}$ & $55(28.9)$ & $35(18.9)$ & $37(12.8)$ & $<\mathbf{0 . 0 0 1}$ \\
Additional small bowel resection & $14(7.4)$ & $12(6.5)$ & $11(3.8)$ & 0.205 \\
Minimally invasive approach & $99(52.7)$ & $113(62.1)$ & $196(68.3)$ & $\mathbf{0 . 0 0 3}$ \\
Protective ostomy & $6(3.2)$ & $20(10.8)$ & $14(4.8)$ & $\mathbf{0 . 0 0 4}$ \\
Adhesiolysis & $59(32.1)$ & $74(40.9)$ & $99(34.5)$ & 0.186 \\
Bowel anastomosis & $123(64.7)$ & $157(84.9)$ & $253(87.5)$ & $<\mathbf{0 . 0 0 1}$ \\
Anastomosis & & & & \\
$\quad$ Hand sewn & $23(18.7)$ & $28(17.8)$ & $43(17.0)$ & 0.918 \\
\hline
\end{tabular}

Significant values are indicated in bold characters

clean, II-clean contaminated, III-contaminated, IV-infectious) [7]. Main surgeon was the surgeon actually performing the operation.

All patients were treated within a comprehensive enhanced recovery after surgery (ERAS) pathway, which has been implemented in Lausanne in 2011 for elective and in 2012 for emergency colectomies $[8,9]$.

Patient's outcomes were adjusted for malignancy, laparoscopy, and emergency, as they were the most relevant clinical confounding factors. Converted patients were analyzed in the laparoscopic group in an intention-to-treat analysis.

\section{Surgeons and surgical setting}

Fellows were surgeons with completed general surgical training (board certified surgeons). Surgeries assigned to the group fellows were procedures that were independently performed by fellows without supervision by a consultant. Consultants (DH, MH, and ND) were three board certified colorectal surgeons by the Swiss Society for Visceral Surgery and EBSQ Coloproctology (DH and $\mathrm{MH})$. All procedures are standardized by the consultants $[10,11]$. Teaching procedures were defined as procedures performed at least to a degree of $75 \%$ by fellows with direct, continuous, and close (face-to-face) supervision by one of the consultants. If less than $75 \%$ teaching occurred, the procedure was assigned to the group consultant. If an operation was taught or not was upon discretion of the consultant and labeled directly at the end of the intervention by the fellow. As a general rule, procedures were taught in the setting of this academic institution unless considered not suitable by the consultant in the first place. Reasons not to teach an operation were insurance status (patients with private insurance operated by consultant according to Swiss policies) and consultants' appraisal of expected difficulty.

Of note, in the present institution, fellows are on-call and present on site over the entire year, working in 12-h shifts. Emergency procedures during night shifts are thus performed by fellows, either alone or in presence of the on-call consultant if needed. For particularly unstable or critical patients, a twostage strategy has been defined (damage control by the fellow, second look at 36-48 $\mathrm{h}$ in presence of a consultant [12-14]). This strategy was chosen based on pre-defined hemodynamic criteria (severe lactic acidosis, vasopressors for inotropic management), independently of the time of surgery or availability of a consultant. Sub-group analysis was performed for procedures performed during night-time (6 pm-6 am).

\section{Outcomes/study endpoints}

The primary endpoint was the rate of intraoperative adverse events, defined as any deviation from the ideal intraoperative course, given the indication for surgery and the interventions conform to current guidelines [15]. They were assessed immediately after the surgical procedure in the above-described database by the operating surgeon.

Secondary endpoints regrouped conversion rate, bleeding complications, operating time, or any other adverse events 
such as organ lesions or wound contamination. All endpoints were labeled intraoperative outcomes.

Conversion to open approach was further studied in two ways: First, time to conversion was measured. Secondly, type of conversion was assessed; whereas pre-emptive conversion was defined as conversion before an adverse event occurred, contrarily to reactive conversion as a consequence of an adverse event. Bleeding was studied in two ways; unusual bleeding - defined as abnormally important blood loss considering the usual amount of blood loss for the respective procedure (estimated at the main surgeons' discretion) and need of intraoperative transfusion. Operating duration was the time between incision and completed skin closure.

\section{Statistical analysis}

All statistical analyses were carried out using the Stata Software (v. 14.2, StataCorp, College Station, TX, USA).

Categorical data were summarized as raw frequencies and relative percentages. Differences in categorical distribution between independent groups were assessed using the Chisquared test, or Fisher's exact test in case of low sample size. Continuous data were summarized as median, interquartile range (IQR), and range. Differences in medians between independent groups were assessed using the Kruskall-Wallis test.

Multinomial logistic regression was used to derive the probabilities for each patient of being assigned to each of the three surgical settings (fellow, consultant, or teaching) according to the following covariates: malignancy, laparoscopy, and emergency indication. The probability for each patient of being assigned to his actual surgical setting was then used in an inverse treatment probability weighting (IPTW) analysis.
Weighted logistic regression was used to assess the effect of surgical setting on binary outcomes, and results were reported as odds ratio (OR) and 95\% confidence intervals. For continuous outcomes, weighted linear regression was used, and results were reported as beta coefficients and $95 \%$ confidence intervals. In each case, the fellow group was set as reference.

All statistical tests were two-sided and a level of 0.05 was used to indicate statistical significance.

\section{Results}

The study cohort consisted of 664 colectomies, allocated to the three groups: fellow, consultant, and teaching. There were respectively 190 (28.6\%), 185 (27.9\%), and 289 (43.5\% procedures in each group. Regarding patient's demographic details displayed in Table 1, there were no statistical differences regarding gender, age, and body mass index (BMI). No differences were found either for immunosuppressive status or previous surgeries. The three groups differed regarding age ( $p$ value $=0.005)$, ASA category $(p$ value $<0.001)$, diagnostic categories $(p$ value $<0.001$ ), Charlson Comorbidity Index $(\mathrm{CCI})(p$ value $=0.005)$, and malignancy $(p$ value $<0.002)$.

Surgical details are depicted in Table 2 . The three groups differed regarding emergency indication $(p$ value $<0.001$ ), wound contamination class ( $p$ value $<0.001)$, minimally invasive approach ( $p$ value $<0.003$ ), protective ostomy ( $p$ value $<0.004)$, and realization of a bowel anastomosis $(p$ value $<$ $0.001)$.

Figure 1 illustrates the distribution of covariates that were used to derive probabilities of treatment among the three groups, before and after weighting. Homogenous distribution regarding the three covariates after matching was achieved.
Fig. 1 The distribution of covariates that were used to derive probabilities of treatment among the three groups, before and after weighting
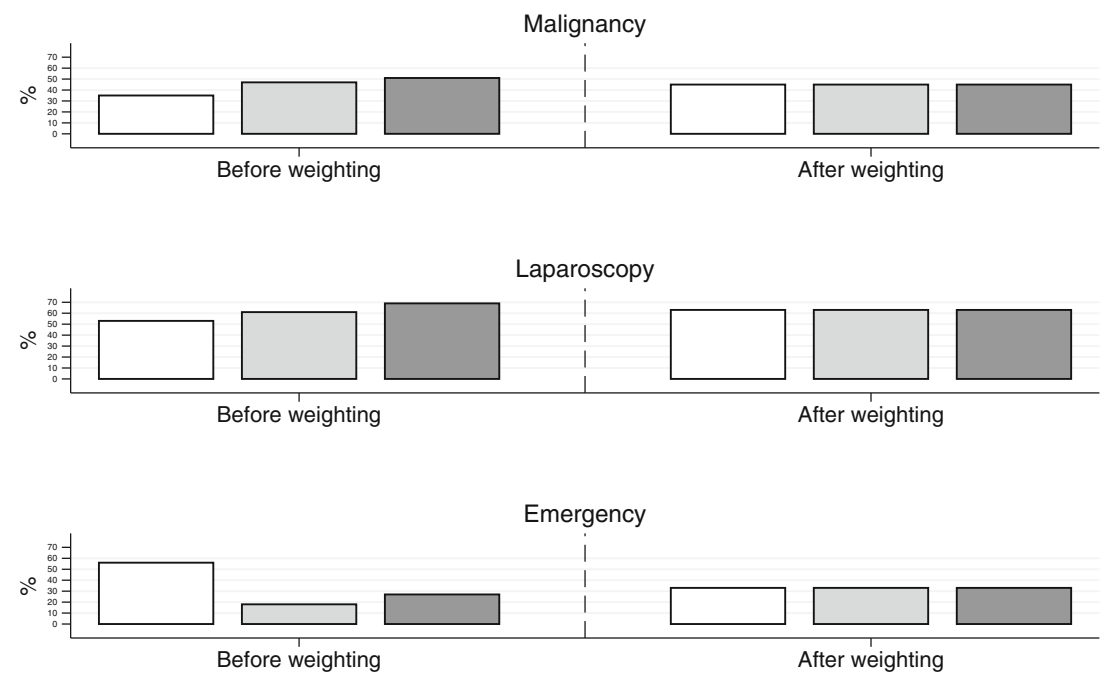

$\square$ Fellow $\square$ Consultant $\square$ Teaching


Intraoperative binary and linear outcomes are illustrated in Fig. 2a, b, respectively. Detailed numbers are available as online appendix (Table S1 and Table S2). None of the outcomes differed significantly.

\section{Intraoperative adverse events}

Intraoperative adverse events occurred in $8 \%$ of cases in the fellow group, $15 \%$ in the consultant group and in $10 \%$ of teaching procedures ( $p$ value 0.098). Observed adverse events $(n=67)$ were small or large bowel transmural lesions in 51 patients ( $7.6 \%$ of all surgeries), serosa lesions in 6 patients $(0.9 \%)$, urinary tract lesions in 6 patients $(0.9 \%)$, and technical issues (i.e., stapler dysfunction) in 4 procedures $(0.6 \%)$.
After weighting, intraoperative adverse event rates did not differ between the three groups (fellow taken as reference, $O R$ for consultant $1.448(0.728-2.878), p$ value $=0.282$; OR for teaching $0.689(0.295-1.609, p$ value $=0.381)$.

\section{Conversion}

Overall conversion rate was $26 \%$ in the fellow group, $17 \%$ in the consultant group, and 20\% in teaching procedures ( $p$ value 0.280 ). After weighting, conversion rates did not significantly differ between the three groups (OR $0.748(0.329-1.515), p$ value $=0.412 ;$ OR $1.025(0.537-1.954), p$ value $=0.940)$.

Conversion was pre-emptive in $79 \%$ in the fellow group, $84 \%$ in the consultant and $87 \%$ in teaching procedures $(p$ value 0.737 ). Pre-emptive conversion rates after weighting
Fig. 2 a, b Intraoperative binary and linear outcomes
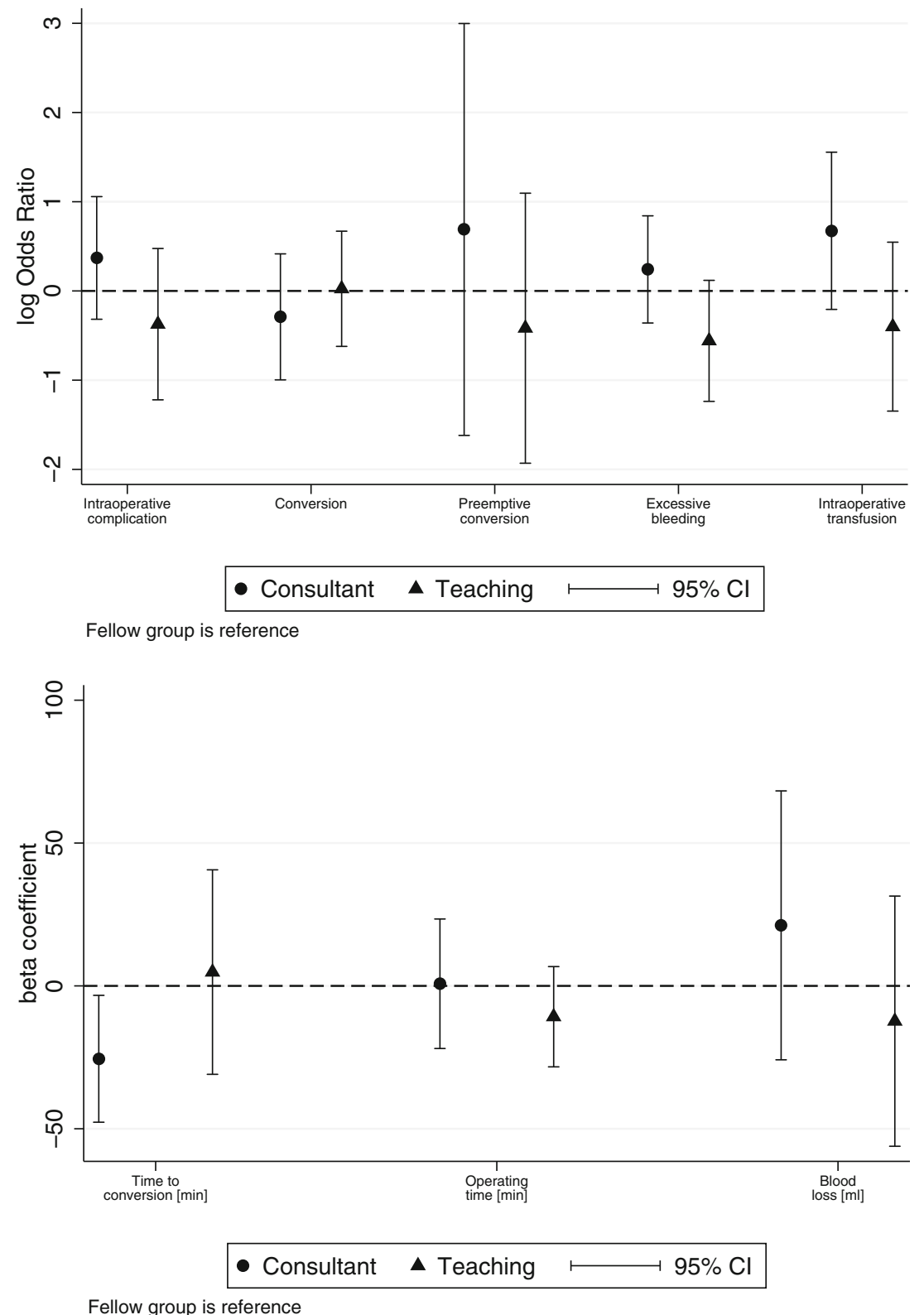
were not statistically significant (OR 1.994 (0.198-20.032), $p$ value $=0.552 ;$ OR $0.659(0.145-2.991), p$ value $=0.583)$.

Median time to conversion was $25 \mathrm{~min}$ (IQR ( $\mathrm{min}$ ) 15-65) in the fellow group, $30 \mathrm{~min}(\mathrm{IQR}(\mathrm{min}) 10-60)$ in the consultant group, and $41 \mathrm{~min}$ (IQR (min) 18-90) ( $p$ value 0.288 ) in teaching procedures. After weighting, time to preemptive conversion was shorter when procedures were performed by consultants (beta coefficient $-25.51(-47.71-3.31), p$ value $=$ $0.025)$, while no difference was found for the teaching group (beta coefficient $4.48(-30.95-40.62), p$ value $=0.788)$.

\section{Bleeding}

Median estimated intraoperative blood loss (EBL) was $50 \mathrm{ml}$ (IQR 20-100) in the fellow group, $100 \mathrm{ml}$ (IQR 20-200) in the consultant group, and $50 \mathrm{ml}$ (IQR 20-100) in teaching procedures ( $p$ value 0.404). After weighting, no difference was found between the three groups (beta coefficient 21.19 $(-25.87-68.25), p$ value $=0.368$; beta coefficient $-12.34(-$ 56.13-31.44), $p$ value $=0.573$ ).

Intraoperative need for transfusion was $7 \%$ in the fellow group, $9 \%$ in the consultant group, and 5\% in teaching procedures $(p$ value 0.226$)$. Rates after weighting did not differ among the three groups (OR $1.962(0.813-4.735), p$ value $=$ 0.127; OR $0.670(0.260-1.727), p$ value $=0.397)$. Of note, overall rate of intraoperative transfusion was $10 \%$ in emergency and $3 \%$ in elective cases $(p<0.001)$, and these rates did not differ significantly either among the three study groups.

Unusual bleeding was $12 \%$ in the fellow group, $18 \%$ in the consultant group, and $17 \%$ in teaching procedures $(p$ value 0.226 ). Rates of unusual bleeding after weighting did not differ in the three groups (OR $1.273(0.698$ $2.321), p$ value $=0.422$; OR $0.572(0.290-1.126), p$ value $=0.099$ ).

\section{Operating time}

Median operating time was $152 \mathrm{~min}$ (IQR (min) 106-190) in the fellow group, $169 \mathrm{~min}$ (IQR (min) 109-262) in the consultant group, and $176 \mathrm{~min}$ (IQR (min) 129-223) ( $p$ value < 0.001 ) in teaching procedures. After matching, operating time did not differ in the three groups (beta coefficient $0.76(-21.91-23.42), p$ value $=0.947$; beta coefficient $10.79(-28.34-6.75), p$ value $=0.919)$.

\section{Operations at night-time (6 pm-6 am)}

In total, 79 procedures (12\%) were performed between $6 \mathrm{pm}$ and 6 am (28 (35\%) between $6 \mathrm{pm}$ and $10 \mathrm{pm}, 34(43 \%)$ between $10 \mathrm{pm}$ and $2 \mathrm{am}$, and $17(22 \%)$ between 2 am and $6 \mathrm{am}$. The majority of patients underwent surgery for diverticulitis (64 patients, $81 \%$ ), while 13 patients (16\%) and 2 patients $(3 \%)$ were operated for colon cancer and IBD, respectively. During these times, 64 procedures $(81 \%)$ were performed by fellows, $6(8 \%)$ by consultants ( 4 diverticulitis and 2 cancer cases), and $9(10 \%)$ were teaching procedures (7 diverticulitis and both IBD cases).

\section{Discussion}

Among 664 colectomies analyzed in this study, intraoperative adverse event did not differ significantly when comparing the three study groups: fellows, consultants, and taught trainees, after adjustment of the three groups. Further, bleeding, operating time, and conversion rates were similar regardless of the setting. The structured and standardized teaching environment in the present institution might account for these encouraging outcomes.

Surgery, among all disciplines of medicine, had ever since its early beginnings placed a strong emphasis on practical training [16]. With the fast evolution of technologies in recent years requiring a continuous adaption of practice and evidence of benefits within high-volume centers [17, 18], the surgeon is under constant pressure to perform well on one hand, and cope with his duty of teaching on the other hand. As expected, intraoperative adverse event have a negative impact on postoperative course [19], highlighting the importance of wellstructured and meticulous teaching. Academic institutions carry the burden of education, with economic and political imperatives that might not provide the ideal external preconditions for young trainees' needs [20-22].

The influence of teaching on postoperative outcomes has been previously studied in cancer patients, either for minimally invasive or open surgery [23,24]. Although some studies showed that surgical adverse event were more likely to occur during early years of practice [25], a study from Borowski et al. showed no negative impact of teaching on surgical outcomes, with no differences in anastomotic leak rates or operative mortality. A study from Montroni et al. including 139 patients comparing outcomes between surgeries performed either by resident or by attending showed no differences in oncological accuracy (equal number of node count), respectively $21 \%$ vs. $25 \%$ morbidity and 3.5 vs. $5.8 \%$ mortality rate according to P-POSSUM. Length of surgery was equivalent in the two groups (159 $\mathrm{min}$ ) [5, 6]. Other outcomes than intraoperative technical adverse event have been studied, with no harm described in teaching settings [4]. The present study focused on intraoperative adverse events to assess the safety of surgical teaching, since postoperative outcomes are influenced by numerous patient- and disease-related factors and compliance to perioperative care pathways and thus not specific enough [3].

As a common conclusion, all mentioned studies emphasize the need of appropriate teaching conditions. The present institution provides a standardized teaching environment. First, only three board-certified senior consultants are in charge of 
concerted training. Every part of the procedure, starting with patients' installation through use of surgical instruments and surgical technique, was standardized through hands-on and written guidelines [10, 11]. Further, ERAS guidelines by itself help through standardized pre- and perioperative care [26, 27]. This standardized technique might provide useful guidance for less experienced surgeons to acquire surgical skills and to gain independency and safety even in stressful situations, i.e., management of challenging procedures during night shifts [28-31]. The present results of equal intraoperative outcomes might thus be mainly the result of standardization and structured surgical education [32-34].

Pre-emptive conversion was performed earlier during the procedure by consultants, probably as a result of surgical experience.

The present study included elective and emergency cases likewise, limiting thus selection bias (all comers). This unselected approach was responsible for the observed differences among the three study groups regarding patient demographics and disease presentation at time of surgery (Tables 1 and 2). In consequence, statistical adjustment was performed regarding emergency procedures (preferably performed by unsupervised fellows), minimally invasive approach (to account for learning curve [35-37] and advanced skills of consultants), and malignant indications (mainly performed in presence of consultants). The only significant difference in analyzed outcomes was the shorter time to conversion in the consultant group, pointing out superiority of strategic thinking in more experienced surgeons.

\section{Limitations}

There are some limitations to this study that need to be addressed. The retrospective setting could lead to selection and recall bias. This drawback was faced by regular, prospective cross-checking of data by consultant surgeons. Several definitions in this study were subjective, starting with the definition of teaching. Even though a national cut-off of $75 \%$ was set (according to the definition of the Swiss Visceral surgery society), evaluation of when $75 \%$ threshold was reached remains subjective. However, the decision whether an operation was taught or not was done by the trainee, reflecting his/her satisfaction of the teaching process (or not). Challenging situations or particularly difficult steps of the procedure might have been managed preferably by consultants, which might be source of inherent bias for every study on surgical teaching. Further reasons for a consultant to take over the operation were unexpected difficulties due to anatomical or technical reasons or time issues, situations which however could hardly be summarized since unique for each procedure. Other subjective assessment concerned bleeding. Also, cross-checked with anesthesiologists and based on actually observed estimated blood loss, it was finally recorded by surgeons, which could lead to erroneous measurements. Emergency surgeries at night have been mainly performed by fellows since on-site $24 / 7$. This obvious bias was faced by statistical adjusting of the three groups for emergencies, surgical approach, and presence of malignancy (Fig. 1). Encouraging results of the present study might thus emphasize acquisition of sufficient skills and independency to manage these stressful situations as a result of standardized teaching. This study focused solely on intraoperative outcomes. Differences in postoperative adverse event among the three groups were not assessed, and thus, the present results cannot be extrapolated to postoperative outcomes. However, the standardized approach with only three different expert surgeons over the entire study period made the assessment of intraoperative complications particularly interesting. Finally, items related to surgical expertise including management of stressful situations, surgical strategy, and technical aspects were not compared between fellows and consultants in the setting of this study.

\section{Conclusion}

The present study displayed no differences in intraoperative adverse events when comparing fellows, consultants, and taught trainees. A structured and standardized teaching environment allowed less experienced surgeons to safely perform colonic resections, even without the presence of an experienced senior surgeon. Hence, surgical teaching should be promoted for the sake of surgical quality.

\section{Compliance with ethical standards}

This study was approved by the Institutional Review Board (Commission cantonale d'éthique de la recherche sur l'être humain CER-VD, \# 201701971). The study was conducted according to the STROBE criteria and registered under www.researchregistry.com (UIN research registry \# 38444).

Conflict of interest The authors declare that they have no conflict of interest.

\section{References}

1. Gronnier C, Grass F, Petignat C, Pache B, Hahnloser D, Zanetti G et al (2017) Influence of enhanced recovery pathway on surgical site infection after colonic surgery. Gastroenterol Res Pract 2017: 9015854

2. Kirchhoff P, Dincler S, Buchmann P (2008) A multivariate analysis of potential risk factors for intra- and postoperative complications in 1316 elective laparoscopic colorectal procedures. Ann Surg 248(2): 259-265

3. Studer P, Inderbitzin D (2009) Surgery-related risk factors. Curr Opin Crit Care 15(4):328-332

4. Grass F, Pache B, Petignat C, Moulin E, Hahnloser D, Demartines N, Hübner M (2018) Impact of teaching on surgical site infection after colonic surgery. J Surg Educ 
5. Montroni I, Ghignone F, Rosati G, Zattoni D, Manaresi A, Taffurelli M, Ugolini G (2014) The challenge of education in colorectal cancer surgery: a comparison of early oncological results, morbidity, and mortality between residents and attending surgeons performing an open right colectomy. J Surg Educ 71(2):254-261

6. Borowski DW, Ratcliffe AA, Bharathan B, Gunn A, Bradburn DM, Mills SJ, Wilson RG, Kelly SB, the members of the Northern Region Colorectal Cancer Audit Group (NORCCAG) (2008) Involvement of surgical trainees in surgery for colorectal cancer and their effect on outcome. Color Dis 10(8):837-845

7. Emori TG, Culver DH, Horan TC, Jarvis WR, White JW, Olson DR, Banerjee S, Edwards JR, Martone WJ, Gaynes RP, Hughes JM (1991) National nosocomial infections surveillance system (NNIS): description of surveillance methods. Am J Infect Control 19(1):19-35

8. Gustafsson UO, Scott MJ, Schwenk W, Demartines N, Roulin D, Francis N, McNaught CE, MacFie J, Liberman AS, Soop M, Hill A, Kennedy RH, Lobo DN, Fearon K, Ljungqvist O (2012) Guidelines for perioperative care in elective colonic surgery: enhanced recovery after surgery (ERAS (R)) society recommendations. Clin Nutr 31(6):783-800

9. Roulin D, Blanc C, Muradbegovic M, Hahnloser D, Demartines N, Hubner M (2014) Enhanced recovery pathway for urgent colectomy. World J Surg 38(8):2153-2159

10. Kummer A, Slieker J, Grass F, Hahnloser D, Demartines N, Hubner M (2016) Enhanced recovery pathway for right and left colectomy: comparison of functional recovery. World J Surg 40(10):2519-2527

11. Hubner M, Larson DW, Wolff BG (2012) "How I do it"-radical right colectomy with side-to-side stapled ileo-colonic anastomosis. J Gastrointest Surg 16(8):1605-1609

12. Ordonez CA, Pino LF, Badiel M, Sanchez AI, Loaiza J, Ballestas L et al (2011) Safety of performing a delayed anastomosis during damage control laparotomy in patients with destructive colon injuries. J Trauma 71(6):1512-1517 discussion 7-8

13. Miller PR, Chang MC, Hoth JJ, Holmes JH, Meredith JW (2007) Colonic resection in the setting of damage control laparotomy: is delayed anastomosis safe? Am Surg 73(6):606-609 discussion 9-10

14. Smith IM, Beech ZK, Lundy JB, Bowley DM (2015) A prospective observational study of abdominal injury management in contemporary military operations: damage control laparotomy is associated with high survivability and low rates of fecal diversion. Ann Surg 261(4):765-773

15. Rosenthal R, Hoffmann H, Clavien PA, Bucher HC, Dell-Kuster S (2015) Definition and classification of intraoperative complications (CLASSIC): Delphi study and pilot evaluation. World J Surg 39(7): 1663-1671

16. Riskin DJ, Longaker MT, Gertner M, Krummel TM (2006) Innovation in surgery: a historical perspective. Ann Surg 244(5): 686-693

17. Nguyen NT, Paya M, Stevens CM, Mavandadi S, Zainabadi K, Wilson SE (2004) The relationship between hospital volume and outcome in bariatric surgery at academic medical centers. Ann Surg 240(4):586-593 discussion 93-4

18. Schmidt CM, Turrini O, Parikh P, House MG, Zyromski NJ, Nakeeb A et al (2010) Effect of hospital volume, surgeon experience, and surgeon volume on patient outcomes after pancreaticoduodenectomy: a single-institution experience. Arch Surg 145(7):634-640

19. Riss S, Mittlbock M, Riss K, Chitsabesan P, Stift A (2014) Intraoperative complications have a negative impact on postoperative outcomes after rectal cancer surgery. Int J Surg 12(8):833-836

20. Stuebing EA, Miner TJ (2011) Surgical vampires and rising health care expenditure: reducing the cost of daily phlebotomy. Arch Surg 146(5):524-527

21. Blackstone ME, Miller RS, Hodgson AJ, Cooper SS, Blackhurst DW, Stein MA (1995) Lowering hospital charges in the trauma intensive care unit while maintaining quality of care by increasing resident and attending physician awareness. J Trauma 39(6):1041-1044

22. Covington MF, Agan DL, Liu Y, Johnson JO, Shaw DJ (2013) Teaching cost-conscious medicine: impact of a simple educational intervention on appropriate abdominal imaging at a communitybased teaching hospital. J Grad Med Educ 5(2):284-288

23. Basse L, Jakobsen DH, Bardram L, Billesbolle P, Lund C, Mogensen $\mathrm{T}$ et al (2005) Functional recovery after open versus laparoscopic colonic resection: a randomized, blinded study. Ann Surg 241(3):416-423

24. Kennedy RH, Francis A, Dutton S, Love S, Pearson S, Blazeby JM, Quirke P, Franks PJ, Kerr DJ (2012) EnROL: a multicentre randomised trial of conventional versus laparoscopic surgery for colorectal cancer within an enhanced recovery programme. BMC Cancer 12:181

25. Campbell RJ, El-Defrawy SR, Gill SS, Whitehead M, Campbell EL, Hooper PL et al (2017) New surgeon outcomes and the effectiveness of surgical training: a population-based cohort study. Ophthalmology 124(4):532-538

26. Gustafsson UO, Scott MJ, Schwenk W, Demartines N, Roulin D, Francis N, McNaught CE, MacFie J, Liberman AS, Soop M, Hill A, Kennedy RH, Lobo DN, Fearon K, Ljungqvist O (2013) Guidelines for perioperative care in elective colonic surgery: enhanced recovery after surgery (ERAS $((\mathrm{R})))$ society recommendations. World J Surg 37(2):259-284

27. Hubner M, Addor V, Slieker J, Griesser AC, Lecureux E, Blanc C et al (2015) The impact of an enhanced recovery pathway on nursing workload: a retrospective cohort study. Int J Surg 24(Pt A):45-50

28. Rieger A, Stoll R, Kreuzfeld S, Behrens K, Weippert M (2014) Heart rate and heart rate variability as indirect markers of surgeons' intraoperative stress. Int Arch Occup Environ Health 87(2):165-174

29. Kang S, Jo HS, Boo YJ, Lee JS, Kim CS (2015) Occupational stress and related factors among surgical residents in Korea. Ann Surg Treat Res 89(5):268-274

30. Yeo H, Viola K, Berg D, Lin Z, Nunez-Smith M, Cammann C, Bell RH, Sosa JA, Krumholz HM, Curry LA (2009) Attitudes, training experiences, and professional expectations of US general surgery residents: a national survey. JAMA 302(12):1301-1308

31. Brunschot DM, Hoitsma AJ, van der Jagt MF, d'Ancona FC, Donders RA, van Laarhoven CJ et al (2016) Nighttime kidney transplantation is associated with less pure technical graft failure. World J Urol 34(7):955-961

32. Page AJ, Gani F, Crowley KT, Lee KH, Grant MC, Zavadsky TL et al (2016) Patient outcomes and provider perceptions following implementation of a standardized perioperative care pathway for open liver resection. Br J Surg 103(5):564-571

33. Muller MK, Dedes KJ, Dindo D, Steiner S, Hahnloser D, Clavien PA (2009) Impact of clinical pathways in surgery. Langenbeck's Arch Surg 394(1):31-39

34. Grass F, Cachemaille M, Blanc C, Fournier N, Halkic N, Demartines N, Hübner M (2016) Is standardized care feasible in the emergency setting? A case matched analysis of patients undergoing laparoscopic cholecystectomy. BMC Surg 16(1):78

35. Schlachta CM, Mamazza J, Gregoire R, Burpee SE, Pace KT, Poulin EC (2003) Predicting conversion in laparoscopic colorectal surgery. Fellowship training may be an advantage. Surg Endosc 17(8):1288-1291

36. Reissman P, Cohen S, Weiss EG, Wexner SD (1996) Laparoscopic colorectal surgery: ascending the learning curve. World J Surg 20(3):277-281 discussion 82

37. Tekkis PP, Senagore AJ, Delaney CP, Fazio VW (2005) Evaluation of the learning curve in laparoscopic colorectal surgery: comparison of right-sided and left-sided resections. Ann Surg 242(1):83-91 